\title{
A CRIMINOLOGIA E AS ESCOLAS CRIMINOLÓGICAS E SUAS INFLUÊNCIAS NA FORMAÇÃO DE UM PERFIL CRIMINÓGENO NAS SOCIEDADES
}

\section{ARTIGO ORIGINAL}

SARAIVA, Barbara Frazão ${ }^{1}$

SARAIVA, Barbara Frazão. A criminologia e as escolas criminológicas e suas influências na formação de um perfil criminógeno nas sociedades. Revista Científica Multidisciplinar Núcleo do Conhecimento. Ano 05, Ed. 05, Vol. 07, pp. 127 136. Maio de 2020. ISSN: 2448-0959, Link de acesso: https://www.nucleodoconhecimento.com.br/lei/escolas-criminologicas

\section{RESUMO}

O artigo em tela visa realizar uma análise histórica da criminologia destacando as mudanças relacionadas às posições das Escolas Criminológicas, no tocante ao perfil do criminoso e seu comportamento desviante no decorrer do tempo e a influência disso no meio social. A fim de realizar as discussões pertinentes sobre a temática, o estudo tomará forma a partir de uma revisão da literatura, que, por sua vez, proporse-á aludir sobre aspectos importantes que se destacam no domínio das teorias criminais. Eles são cruciais para que seja possível realizar um panorama histórico brasileiro, e, a partir dele, realizar as reflexões necessárias sobre o perfil criminal, tendo como ênfase o brasil. Pensar em tais questões justifica a relevância deste estudo.

Palavras-chave: Criminologia, Escolas Criminológicas, mudanças, meio social.

${ }^{1}$ Bacharel Em Direito Pela Universidade Federal Fluminense Em 2012. 


\section{INTRODUÇÃO}

Esta proposta visa analisar, do ponto de vista da ciência criminal, sobre as transformações tangentes à construção da imagem do criminoso. Para tanto, apoiarse-á em conceitos e teorias das Escolas Criminológicas a fim de verificar a sua expressividade no meio em que se vive. Inicialmente, discutir-se-á sobre o que é a criminologia, o objeto dessa ciência e sobre o método por ela empregado, bem como sobre a posição de diversos autores sobre o tema. Em seguida, será realizada uma breve análise histórica das Escolas do pensamento criminológico, ressaltando as percepções de cada uma em relação à análise do perfil criminógeno. Trata-se de um trabalho de revisão que se apoia no método dedutivo, e, assim, tem como base as pesquisas bibliográficas.

Devido à abordagem metodológica aqui empregada, a pesquisa versará sobre aspectos que permeiam o campo da criminologia. Verificar-se-á, também, como esses elementos demonstram a importância de se pensar a ciência criminológica do ponto de vista social, pois a partir dessa assimetria com a sociedade é possível que haja uma melhor compreensão do perfil criminógeno. Visa-se identificar os delinquentes por meio da apresentação de visões distintas acerca da justificação do delito, destacando que tais teorias são frutos do pensamento humano, e, dessa forma, essas visões são influenciadas por múltiplas relações humanas condicionantes de épocas.

\section{A CIÊNCIA CRIMINAL E AS ESCOLAS CRIMINOLÓGICAS: A FORMAÇÃO DO PERFIL CRIMINÓGENO}

\subsection{O OBJETO DA CIÊNCIA CRIMINAL}

Inicialmente, conforme Silva e Miquelon (2018), há que se frisar que a ciência criminológica não possui uniformidade no que tange a sua definição, pois, segundo os autores, existem diversas conceituações dadas para a mesma que variam conforme o autor. Destarte, os doutrinadores Antônio García-Pablos de Molina e Luiz Flávio Gomes são referências na temática, pois cunham a criminologia e os seus conceitos a partir de uma ótica empírica e interdisciplinar. Trata-se do estudo do crime, da 
pessoa do infrator, da vítima e do controle social do comportamento delitivo (MOLINA; GOMES, 2002). Segundo Lola Anyar, a Criminologia estuda a criação das normas criminais - passando pelas normas sociais que envolvem as de cunho penal - o processo de sua negação, o estabelecimento dessas normas e a reação social decorrente do seu efeito prático (CASTRO, 1983).

Para muitos, a Criminologia é uma ciência humana e social que tem como escopo o estudo de seus objetos, quais sejam: o delito, o delinquente, a vítima e o controle social. Assim sendo, Schecaria (2012, p. 44) alude que: "apesar de possuir diversos conceitos, a Criminologia pode ser entendida como ciência empírica e multidisciplinar que busca entender diversos processos, dentre eles o social, que envolvem seu objeto, qual seja: o delito, o delinquente, a vítima e o controle social". Para Schecaria (2012) há uma relação estreita entre a Criminologia e o Direito Penal que faz com que ambos possuam o mesmo objeto, qual seja: o crime e suas variáveis, mas se diferenciam quanto ao foco dado aos seus estudos. Deve-se compreender a ciência penal como uma norma de caráter repressivo, visto que compreende o crime como uma conduta social anormal.

A partir dessa perspectiva, o Direito Penal entende que é preciso que haja uma punição mediante sua violação. A Criminologia, por sua vez, compreende o crime, o criminoso e as suas condutas por meio de uma ótica causal-explicativa, e, assim, propõe meios preventivos para que esses criminosos deixem de o ser. Nesse sentido, entende Pimentel (2007, p. 81) que é: "importante salientar que as matérias supracitadas conceituam de formas diferentes o delito, entendendo o Direito Penal como delito a ação ou omissão típica, ilícita e culpável e a Criminologia, o entende como um problema social que envolve aspectos morais, religiosos, econômicos, filosóficos, políticos, históricos, biológicos, psicológicos e outros". Ressalta-se a importância do estudo do criminoso conforme o passar do tempo, pois a caracterização do delinquente, conforme os parâmetros das Escolas Criminológicas, dita caminhos sancionatórios para o Direito Penal, assim como permitem uma análise sociológica de cada momento histórico. 
No que se refere ao delinquente como objeto de estudo da ciência criminal, Paula (2013) alude que ele deve ser compreendido como um sujeito histórico, real, complexo, e, portanto, enigmático por essência. É, então, uma pessoa normal, e, assim, o meio em que está influi sobre ela, e, consequentemente, sobre as suas ações. Para Schecaria (2012), outro aspecto importante é o estudo da vítima que sofre com a prática do ato delitivo que pode ser causado por seus próprios atos, por atos de outrem ou até mesmo atos do acaso. Inicialmente, o direito penal desprezava a figura da vítima, focando-se apenas no delinquente, porém, do ponto de vista da ciência criminal, a vítima passou a ser considerada, também, na análise do perfil criminógeno. De acordo com Penteado Filho (2013), há que se considerar três fases no que tange a vítima do ponto de vista penal.

Elas são, respectivamente, a "idade de ouro, a neutralização do poder da vítima e a revalorização da sua importância" (PENTEADO FILHO, 2013, p. 24). A "idade de ouro" é entendida pelos doutrinadores como o período que se perdurou até a Alta Idade Média. Compreendia-se a vítima como núcleo do processo e havia a ocorrência da vingança privada. Conforme França (2018), a segunda fase compreendeu o processo de neutralização da vítima, e, assim, após designado o monopólio punitivo para o Estado, passou-se a utilizar um modelo de processo baseado em ações públicas que prevalece até os dias atuais nos ordenamentos jurídicos mais diversos. Para Viana (2016), existiam, nessa fase, poucas ações penais de caráter privado, e, ainda, raras possibilidades de interferência da vítima no âmbito penal.

A terceira fase, por fim, compreende o redescobrimento do papel da vítima. O estudo da vitimologia permitiu maior aprofundamento no estudo referente à criminalidade, em virtude das informações valiosas prestadas pelas mesmas. Essa ciência é de suma importância, pois, a partir dela, passou-se a analisar os danos sofridos pelas vítimas que se modificam de acordo com os tipos de crimes e a gravidade com que foram cometidos, o que ajudou muito na reintegração das vítimas ao meio social. No tocante ao controle social, destaca-se que é de suma importância a análise da relação de causa e efeito entre o controle social e a criminalidade para o estudo da Criminologia. Conforme sabido, os conflitos são inerentes ao convívio social, podendo ser 
solucionados entre os envolvidos apenas ou com a intervenção estatal, dependendo do grau de reprovabilidade que o crime possuir na sociedade.

De acordo com Molina (2002), o controle social compõe um conjunto de instituições, e, ainda, estratégias e sanções advindas do meio social. Visam, então, a promoção e garantia da segurança e subentende os modelos e normas comunitárias nesse processo. Nesse sentido, desde o início das civilizações, as sociedades estabelecem normas de conduta para que haja um equilíbrio social, constituindo sanções via controle social quando há transgressões das mesmas para manter a ordem social. Assim, Conde (2005, p. 22) preleciona que "o controle social determina, assim, os limites da liberdade humana na sociedade, constituindo, ao mesmo tempo, um instrumento de socialização de seus membros". Importante observar que o controle social penal não surgiu apenas para punir o criminoso, mas também para delimitar ius puniendi por parte do Estado. Para Beccaria (2003, pp. 19-20):

Neste pacto social não estaria apenas à origem do Direito Penal, mas também seu limite, posto que somente a necessidade obriga os homens a ceder uma parcela de sua liberdade; disso advém que cada qual apenas concorda em por no depósito comum a menor porção possível dela, quer dizer, exatamente o que era necessário para empenhar os outros em mantê-lo na posse do restante. A reunião de todas essas pequenas parcelas de liberdade constitui o fundamento do direito de punir. Todo exercício do poder que deste fundamento se afastar constitui abuso e não justiça; é um poder de fato e não de direito; constitui usurpação e jamais um poder legítimo.

Importante ressaltar, considerando o contexto apresentado, que ciências como, por exemplo, a Biologia, Psicologia, Sociologia, Psiquiatria, foram fundamentais para análises criminológicas, servindo, dessa forma, como base para auxílio de estatísticas e observações, necessárias, por sua vez, para definir o método de pesquisa para cada período. Com o passar dos anos e dos métodos, a partir de tais análises interdisciplinares, percebe-se que o delito passou a não ser o único objeto de estudo da Criminologia, uma vez que a referida ciência estabeleceu outros objetos como 
escopo e de igual importância para a realização de análises: o delinquente compreendido a partir de um olhar preventivo e repressivo.

\subsection{AS ESCOLAS CRIMINOLÓGICAS: MÉTODOS PARA ANALISAR OS PERFIS CRIMINÓGENOS}

No tocante aos períodos históricos da Criminologia, desde a Antiguidade (período designado como pré-científico), já existiam textos esparsos que revelavam a preocupação com o delito. O período tem como referência o Código de Hamurabi, datado de, aproximadamente, 1772 a. C., baseado na Lei de Talião, com a máxima "olho por olho, dente por dente", na qual pregava a vingança, ou seja, a pena retributiva. Neste período, o crime era entendido sob perspectivas religiosas e sobrenaturais, sendo visto como um pecado, julgado com base nos valores éticos e morais da época. Em relação ao surgimento da Criminologia, há divergência acerca de seu marco inaugural, sendo certo que a doutrina majoritária aufere a data de 1879 e que foi inaugurada pelo antropólogo francês Paul Topinard. A ideia foi disseminada e, em 1885, Raffaele Garófalo empregou o termo ciência do crime, na obra "Criminologia".

A partir de lluminismo, no século XVIII, surge a Escola Clássica, cujos principais expoentes foram Cesare Beccaria, Francesco Carrara e Giovanni Carmignani, caracterizando-se pela adoção do método lógico-abstrato e dedutivo, baseado no silogismo e na fundamentação da responsabilidade penal no livre arbítrio. Nessa fase, cumpre destacar o livro "Dos Delitos e das Penas", escrito em 1764 pelo Marquês de Beccaria. Trata-se de uma crítica ao sistema penal vigente, no qual denuncia torturas, suplícios e penas desproporcionais, colaborando com a reforma do sistema (BECCARIA, 2001). Resta claro que esta Escola não possuía teorias homogêneas, pois seus adeptos divergiam em muitos postulados, porém resta claro que a pena, a responsabilidade penal e o crime eram as ideias caracterizadoras desta mesma.

Assim, as doutrinas jusnaturalista e contratualista, que, a princípio, parecem opostas, acreditavam em normas jurídicas superiores ao Estado, questionando, dessa forma, a legitimidade de sua tirania. Nesse sentido, ensina Baratta (1999, p. 33): "o contrato 
social está na base da autoridade do Estado e das leis; sua função, que deriva da necessidade de defender a coexistência dos interesses individualizados no estado civil, constitui também o limite lógico de todo legítimo sacrifício da liberdade individual mediante a ação do Estado". Destaca, em particular, o exercício do poder punitivo pelo próprio Estado. Em razão disso, adeptos Escola defenderam a restauração da dignidade do homem e seu direito perante 0 Estado, o que contribuiu substancialmente com o Direito Penal.

No final do século XIX, sob inspiração da fisionomia e da frenologia, deu-se início a um período denominado de Científico, o que acarretou o surgimento do Positivismo Criminológico. A Scuola Positiva Italiana tinha como líderes Lombroso, Ferri e Garofalo, sendo que Lombroso é autor da obra "O homem delinquente", publicada em 1876. Ele é considerado pelos doutrinadores como o pai da Criminologia, e, ainda, como o criador da disciplina "Antropologia Criminal". Ele empregou o método empírico em suas investigações e defendeu o determinismo biológico no campo criminal. $O$ médico italiano acreditava, baseado em suas pesquisas médico penitenciárias que utilizavam o método causal explicativo, que o criminoso consistia em uma variedade da espécie humana, afetado por anomalias anatômicas e fisiopsicológicas.

Para ele era certo que traços físicos identificariam o criminoso por natureza. Para tanto, propôs o estabelecimento de um perfil capaz de verificar as pessoas propensas a cometerem delitos. Paula (2013 apud MOLINA, 2002, p. 24), afirma que "a contribuição principal de Lombroso para a Criminologia não reside tanto em sua famosa tipologia (onde destaca a categoria do "delinquente nato") ou em sua teoria criminológica, senão no método que utilizou em suas investigações: o método empírico". Na fase sociológica desta Escola, conforme Paula (2013), na qual se destacou Enrico Ferri, este deu continuidade ao movimento que popularizou os fenômenos criminógenos, antropológicos, físicos e sociais. Além de defender substitutivos penais, o jurisconsulto deu maior ênfase à prevenção dos crimes, além de apresentar a pena não como forma de punir o indivíduo, mas de reajustá-lo ao convívio social. 
Segundo Paula (2013) e Mansoldo (2018) aludem que Ferri censurou os "clássicos" alegando que esses anulavam a teoria sobre a gênese da criminalidade, o que acarretava a constatação fática desta, havendo a sua presença. Ele propôs, como substituição, a adesão a uma ótica "etiológica" acerca desse crime, e, assim, orientava a pesquisa científica a fim de verificar as causas do crime (MOLINA, 2002). Frisava, também, que o criminoso estaria destinado à cometer práticas criminosas em razão do seu contexto de vida, e, dessa forma, sustentava a ideia de que há a inexistência do livre-arbítrio. Já na fase jurídica da Escola, há especial destaque para as contribuições de Garófalo. A sua pesquisa era sobre o crime em si e defendia a relação entre o caráter criminoso com uma anomalia psíquica e moral, introduzindo como critério de medida penal a periculosidade criminal.

Garófalo ocupava o cargo de jurista, e, dessa forma, propôs uma sistematização jurídica à Escola Positiva. Enfatizava-se, sobretudo, princípios como a periculosidade, compreendida como fundamento da responsabilidade do delinquente e a prevenção especial como fim da pena, fundamentando o direito de punir sobre a teoria da Defesa Social e formulando uma definição sociológica do crime natural (BITENCOURT, 2000). Rodrigues (2019) alude que, para Garófalo, a partir do emprego do termo "Castigo", entendido como filosofia, partia-se da premissa de que a pena deve se dar em função de características de cada delinquente, sem se valer, portanto, de critérios convencionais, como, por exemplo, a retribuição ou expiação, a correção, ou, ainda, a prevenção. Cada delinquente é único e demanda sanções diferentes.

Também chamada de Escola Antropológica, Naturalista ou Realista, está se destacou por atuar de forma multidisciplinar, ou seja, recorre à outras ciências, como, por exemplo, a Psiquiatria, a Antropologia, a Sociologia e a Estatística para analisar o comportamento humano. A fim de se realizar uma análise mais completa e detalhada, recorre-se à fatores externos ou internos, como, por exemplo, a causa e o meio em que surge. Nesse contexto, a Escola Positivista compreende que o criminoso escolhe praticar o crime. Essa escolha é livre. Parte-se do princípio, também, de que os fatores que influenciam esse criminoso advém do seu contexto de vida, o que o coloca em um estado de anormalidade, em que a pessoa normal está apta para viver em 
sociedade. As Escolas Clássicas e Positiva, por sua vez, conforme Ribeiro (2017), foram as únicas correntes criminais que, à época, assumiram posições filosóficas distintas.

Posteriormente, adveio a Escola Crítica, que compreende o crime como um fenômeno social e busca explicar e justificar a maneira como os fatores do meio ambiente social atuam sobre a conduta individual, conduzindo o homem à prática delitiva. Essa Escola busca um paradigma de reação social, rompendo com o paradigma etiológico das Escolas anteriores, e, assim, há uma série de discursos que são resultados do conjunto de diversos conhecimentos oriundos de diversos campos do conhecimento. Recorre-se a eles para ilustrar o fenômenos criminal a partir dos saberes das cooperações homogêneas em cada tempo histórico. Por intermédio desses discursos, surgiram várias correntes que procuraram conciliar suas ideias em busca de novos modelos de estudo para a criminologia, tendo o pensamento criminológico sido influenciado por duas visões principais da Macrossociologia.

De acordo com Abreu (2018), a primeira se trata da Teoria da Integração (também conhecida como Teoria do Consenso ou Funcionalista). Essa corrente engloba as Escolas Sociológicas de Chicago, a Teoria da Associação Diferencial, a Teoria da Anomia e a Teoria da Subcultura Delinquente. Assim sendo, visa-se refletir sobre as formas que fazem com que a sociedade funcione perfeitamente, de modo que os sujeitos possam compartilhar de objetivos comuns à coletividade, obedecendo, portanto, as normas existentes. Há, então, associações voluntárias que criam sistemas sociais e partilham de valores semelhantes, fazendo com que a cooperação mútua funcione. Apresentam como elementos a estabilidade, a integração, a coordenação funcional e o consenso. Conforme tal teoria, a mudança social representa uma disfunção.

A segunda foi a Teoria do Conflito Social, na qual estão inseridas a Teoria do Labelling Approach, a Teoria Interacionista e a Teoria Crítica, que entendem o crime como um fenômeno social e seletivo, ligado diretamente à vida em sociedade. Para Bem (2011), a Teoria do Conflito Social compreende e tem como fundamento aspectos como o fato e a ordem e como esses se manifestam na sociedade. Esses elementos se fundam a 
partir da força e da coerção, e, dessa forma, são viabilizados pela dominação de alguns indivíduos perante outros, o que coloca uma parte da sociedade como assujeitados a esses outros. Há, então, uma relação de dominante e dominado.

Tal Teoria foi defendida por vários autores, e, dentre eles, destaca-se Karl Marx, que entende, a partir dos seus escritos teórico-filosóficos, que todo elemento em uma sociedade colaboraria para sua desagregação e transformação. Paula (2013), em seu estudo, enfatiza que o sucesso dessa Escola se deu em razão do fato de que ela se baseia no uso efetivo das informações que subministra a fim de analisar os efeitos políticos criminais. Segundo Molina (2002), apenas essas teorias partem da hipótese de que o crime é um fenômeno seletivo, antes de tudo, social, e, assim, estão ligados à certos processos, estruturas e conflitos sociais, e, em razão disso, deve-se isolar as variáveis.

\section{CONSIDERAÇÕES FINAIS}

Essa reflexão buscou enfatizar e, também, discutir, a partir do ponto de vista histórico, sobre os objetos da Criminologia. Esses são extremamente complexos e devem ser analisados a partir da interdisciplinaridade. Dessa forma, cumpre salientar que o escopo do trabalho não foi esgotar os temas sobre a matéria, pois seria demasiado desgastante analisar as inúmeras teorias desenvolvidas pela mesma. O objetivo do presente artigo foi elucidar os aspectos essenciais tocantes ao domínio da ciência criminal. Primeiramente, analisou-se as Escolas Criminológicas, e, ainda, os seus métodos analíticos para o entendimento dos seus objetos, considerando os variados núcleos sociais.

Conclui-se que a Criminologia é crucial para a compreensão do multifacetado fenômeno criminal inserido nas sociedades. Após pesquisa de cada fase, Escola ou Teoria de caráter criminal, notou-se a relevância do pensamento de cada época no que concerne aos motivos do crime gera no âmbito social, principalmente no que diz respeito às leis penais, em suas formações de tipos penais e políticas criminais. Nesse sentido, apontou-se a importância da análise interdisciplinar, como, por exemplo, histórica, política e social no estudo dos objetos desta ciência para a compreensão 
dos motivos que determinam os fatores que fomentam o mapeamento do perfil criminógeno de cada contexto.

\section{REFERÊNCIAS}

ABREU, N. G. M. Teorias macrossociológicas da criminalidade. Revista Interdisciplinar de Sociologia e Direito, v. 20, n. 3, p. 99-118, 2018.

BARATTA, A. Criminologia Crítica e crítica do Direito Penal: introdução à sociologia do direito penal. Tradução Juarez Cirino dos Santos. $2^{\underline{a}}$ ed. Rio de Janeiro: Freitas Bastos: Instituto Carioca de Criminologia, 1999.

BECCARIA, M. C. Dos delitos e das penas. São Paulo: Ed Martins Claret, 2003.

BEM, S. N. T. C. do. Algumas reflexões sobre o Direito Penal do Inimigo em face da proteção dos direitos fundamentais. 2011. 90 f. Especialização (Pós-Graduação em Direito Penal) - Escola da Magistratura do Estado do Rio de Janeiro, Rio de Janeiro, 2011.

BITENCOURT, C. R. Manual de Direito Penal: parte geral. 6ª . ed. rev. e atual. São Paulo: Saraiva, 2000.

CASTRO, L. A. Criminologia da Reação Social. Tradução de Ester Kosovski. Rio de Janeiro: Editora Forense, 1983.

CONDE, F. M. Direito penal e controle social. Trad. Cíntia Toledo Miranda Chaves. Rio de Janeiro: Ed. Forense, 2005.

FRANÇA, F. B. Evolução Histórica Do Objeto de Estudo da Vitimologia. 2018. Disponível em: https://fernandabf.jusbrasil.com.br/artigos/530481135/evolucaohistorica-do-objeto-de-estudo-da-vitimologia. Acesso em: 13 mai. 2020.

GARÓFALO, R. Criminologia: estudo sobre o direito e a repressão penal seguido de apêndice sobre os termos do problema penal. Campinas: Ed. Pétrias, 1997. 
MANSOLDO, M. C. N. Crimes tributários sob a ótica da criminologia crítica: extinção de punibilidade pelo pagamento do tributo e a teoria do etiquetamento. Revista Quaestio luris, v. 11, n. 2, p. 839-879, 2018.

MOLINA, A. G. P. de. Criminologia: uma introdução a seus fundamentos teóricos. Tradução de: Luiz Flávio Gomes. 3ª. ed. São Paulo: Revista dos tribunais, 2002.

MOLINA, A. G-P.; GOMES, L. F. Criminologia: Introdução a seus fundamentos teóricos; Introdução às bases criminológicas da Lei 9.099/95; Lei dos Juizados especiais Criminais. 8ª . ed. rev. e. atual. São Paul: Revista dos tribunais, 2002.

PAULA, T. B. de. Criminologia: estudo das escolas sociológicas do crime e da prática de infrações penais. 2013. 46 f. Graduação (Bacharel em Direito) - Universidade do Norte Paulista, São José do Rio Preto, 2013.

PENTEADO FILHO, N. S. Manual de Criminologia. 3aㅗ ed. São Paulo: Saraiva, 2013.

PIMENTEL, M. P. O Crime e a Pena na Atualidade. 24로 ed. São Paulo: Atlas, 2007.

RIBEIRO, M. dos. S. Um breve histórico das escolas: clássica, positiva, crítica, moderna alemã e a influência da escola positiva na formação do Código Penal de 1940. 2017. Disponível em: https:/jus.com.br/artigos/59164/criminologia. Acesso em: 13 mai. 2020.

RODRIGUES, E. M. S. Comportamento Criminal do Psicopata. 2019. Disponível em: https://ambitojuridico.com.br/cadernos/direito-penal/comportamento-criminal-dopsicopata/. Acesso em: 13 mai. 2020.

SCHECARIA, S. S. Criminologia. 4 ${ }^{a}$ ed. ver. e. atual. São Paulo: Revista dos Tribunais, 2012.

SILVA, M. A. D.; MIQUELON, E. A. A criminologia clínica: a psicopatia e a exploração da mídia por audiência. 2018. Disponível: https://www.boletimjuridico.com.br/artigos/direito-penal/4148/a-criminologia-clinicapsicopatia-exploracao-midia-audiencia. Acesso em: 13 mai. 2020. 
VIANA, E. Criminologia. 4를 ed. Salvador: Juspodivm, 2016.

Enviado: Abril, 2020.

Aprovado: Maio, 2020. 